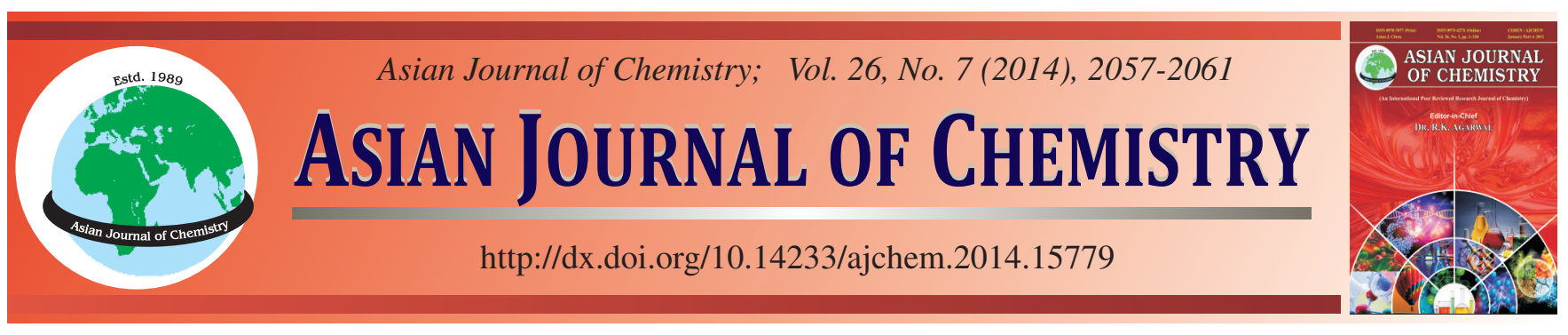

\title{
Optimization of Antibacterial Compounds with Ultrasonic/Microwave Assisted Extraction from Alpinae Oxyphyllae Fructus and its Antibacterial Activities
}

\author{
D. WANG and W.X. CHEN*
}

Department of Food Science and Technology, Hainan University, Haikou, P.R. China

*Corresponding author: Tel: +86 13976121821; E-mail: hnchwx@163.com; qiuqiujazz@126.com

\begin{abstract}
The work was to optimize to enhance the antibacterial activities of ethanol extracts from alpinae oxyphyllae fructus with ultrasonicmicrowave assisted extraction method. And the optimum conditions were as follows: ethanol concentrations $73 \%$, extract temperature 54 ${ }^{\circ} \mathrm{C}$, liquid-material ratio 15 and extract time $46 \mathrm{~min}$. Under these conditions, the significant antibacterial activities expressed as the diameter of inhibition zones could reach $10.43 \pm 1.29 \mathrm{~mm}$, which was higher than traditional hot water extraction methods. On the basis of it, the minimum inhibitory concentration of extract against $E$ coli. and $S$. aureus, respectively was 3.00 and $1.50 \mathrm{mg} / \mathrm{mL}$. Moreover, the content of total polyphenols and flavonoids were obtained, whose content were $7.34 \pm 0.19 \%$ and $5.95 \pm 0.32 \%$ respectively. On further study, the results showed the content of total polyphenols and flavonoids was highly correlated with the antibacterial activities with each $p<0.01(p=0.007$ and $p=0.006)$.
\end{abstract}

Keywords: Alpinae oxyphyllae fructus, Optimization, Antibacterial activities, Polyphenols content, Flavonoids content.

\section{INTRODUCTION}

Alpinia oxyphylla MIQ (Zingiberaceae) is a usual conventional Chinese pharmacological and medicinal herb whose fruits are widely used to treat diarrhea, gastralgia, tonic, polyuria, aphrodisiac, anti-salivation and neuroprotection ${ }^{1-4}$. Studies about alpinae oxyphyllae fructus (AOF), like, the pharmacological mechanism for alpinae oxyphyllae fructus was attributed to anti-aging and sexual-reinforcing activities in experimental in vitro and in vivo systems ${ }^{5,6}$; the protective effect of alpinae oxyphyllae fructus against 6-OHDA-induced neuronal injury involved anti-inflammatory action ${ }^{7}$ and $A \beta-$ induced cell death was protected by the application of water extract of alpinae oxyphyllae fructus in a dose-dependent manner and the effect to protect primary cultured neurons from $\mathrm{N}$-methyl-D-aspartate (NMDA) receptor-mediated glutamate toxicity ${ }^{8}$.

There is considerable interest in alternative/adjuvant approaches for the eradication of infections using biologically active compounds, as food preservatives. The safety of food products with synthetic chemicals can in some cases be in doubt and the products can thus potentially be detrimental to human health ${ }^{9}$. Amongst plants are important sources of bioactive compounds having antibacterial activity and other pharmaceutical effects ${ }^{10}$. In the process of screening for naturally occurring substances with antibacterial effects, we discovered that ultrasonic/microwave assisted extraction (UMAE) on the fruits of alpinae oxyphyllae fructus exhibited significant in vitro.

However, there are few reports regarding the application of preservatives from alpinae oxyphyllae fructus, especially optimization of ultrasonic/microwave assisted extraction (UMAE) of antibacterial compounds from it. This higher efficiency could be attributed to action of microwave irradiation, which produces the disruptions of tissues and cell walls leading to a greater contact area between solid and liquid phase, better access of solvent to valuable components ${ }^{11}$. The possible benefits of ultrasound in extraction are mass transfer intensification, cell disruption, improved penetration and capillary effects ${ }^{12}$. Combining ultrasonic with microwave would show their several advantages.

Plant-derived polyphenols and flavonoids are a large group of naturally occurring phenyl-chromones found in fruits, vegetables, tea and wine. They have been shown to have a wide range of biological activities, including antiallergic, antibacterial, antidiabetic, antiinflammatory, antiviral, antiproliferative, antimutagenic, antithrombotic, anti-carcinogenic and antioxidant activities ${ }^{13}$. This study was to research the relationship between the total polyphenols and flavonoids content with the antibacterial activities.

The first purpose of the present study is to optimize the ultrasonic/microwave assisted extraction (UMAE) conditions 
and compare with traditional hot water extraction. Moreover, there is little information about the MIC of the extract. Consequently, the second purpose is to evaluate the relationship between antibacterial activities of alpinae oxyphyllae fructus and its polyphenols and flavonoids content. It is believed that the extract can be a good chemotherapeutic agent from a naturally occurring material and induce multiple bio-functions in human being.

\section{EXPERIMENTAL}

Alpinae oxyphyllae fructus was purchased from Shounanshan Ginseng Industry Co., Ltd (Wuzhishan, Hainan, China). The antibacterial activity was screened against the Gram-positive bacteria Staphylococcus aureus and Gramnegative bacteria E. coli, obtained from the Food Microbiology Laboratory of Hainan University. All the other chemicals used were of analytical grade.

\section{Extraction procedure}

Pre-treatment of alpinae oxyphyllae fructus: The alpinae oxyphyllae fructus (AOF) samples were vacuum-dried at $60{ }^{\circ} \mathrm{C}$ for $24 \mathrm{~h}$, then smashed and comminuted to pass 40-mesh sieve.

Ultrasonic/microwave assisted extraction: The pretreated alpinae oxyphyllae fructus powder $(15 \mathrm{~g})$ was weighed accurately and then transferred into the flask. Then the flask was transferred into the chamber of the apparatus connected with condensing tubes. Finally, the door of chamber was closed and the program of different microwave temperature and extraction time was set. And the ultrasonic power was always $50 \mathrm{~W}$. When extraction was accomplished, the flask was removed from apparatus. The treated mixture was suction filtrated and supernatants were combined and evaporated with a rotary evaporator and obtained at $-4{ }^{\circ} \mathrm{C}^{14}$.

\section{Assays for antibacterial activity}

Microorganisms: All the bacterial cultures were maintained on nutrient agar at $4{ }^{\circ} \mathrm{C}$ with monthly subcultures in our laboratory.

Disc diffusion assay: The antibacterial activity of the extract was measured by a diffusion test ${ }^{15}$. Sterilized paper discs $(6 \mathrm{~mm})$ were impregnated with different extract prepared in aqueous methanol and placed onto nutrient agar. The plates were incubated at $4{ }^{\circ} \mathrm{C}$ for $1 \mathrm{~h}$ to allow diffusion of the active compounds. Negative controls were prepared using the same solvent. Incubation of plates was performed at $37^{\circ} \mathrm{C}$ for $24 \mathrm{~h}$. Inhibition zones in $\mathrm{mm}$ (without disc paper diameter) around discs were measured. The antibacterial activity was expressed as the diameter of inhibition zones produced by the extract against test microorganisms.

Termination of minimum inhibitory concentration (MIC): Different concentrations $80 \mathrm{mg} / \mathrm{mL}, 240 \mathrm{mg} / \mathrm{mL}, 120$ $\mathrm{mg} / \mathrm{mL}, 60 \mathrm{mg} / \mathrm{mL}, 30 \mathrm{mg} / \mathrm{mL}, 15 \mathrm{mg} / \mathrm{mL}, 7.5 \mathrm{mg} / \mathrm{mL}$ of extract were tested; $1 \mathrm{~mL}$ of each solution was mixed with $9 \mathrm{~mL}$ of Muller Hinton medium and poured into plates. Immediately after solidification, the plates were spot into suspension containing $10^{6} \mathrm{cfu} / \mathrm{mL}$ of each bacterium. The plates were incubated at $37^{\circ} \mathrm{C}$ for $24 \mathrm{~h}$. MIC value was taken as the lowest concentration that produced no visible bacterial growth $^{16}$.
Experimental design of response surface methodology: After determining the preliminary range of the extraction variables though preliminary experiments, a four-variable with ethanol volume $\left(\mathrm{X}_{1}\right)$, solid-liquid ratio $\left(\mathrm{X}_{2}\right)$, extraction time $\left(\mathrm{X}_{3}\right)$, temperature $\left(\mathrm{X}_{4}\right)$ three-level $(-1,0,1)$ Box-Benken design $(\mathrm{BBD})^{17,18}$ was applied to determine the best combination of extraction variables for the antibacterial activities. Twentyseven experiments were augmented with three times and carried out at the center points to evaluate the pure error. And the bacteria tested by the disc diffusion assay in this RSM was E. coli.

Regression analysis was performed for the experimental data and was fitted into the empirical second order polynomial model, as shown in the following equation:

$$
\mathrm{Y}+\alpha_{0}=\sum_{\mathrm{i}=1}^{4} \alpha_{\mathrm{i}} \mathrm{X}_{\mathrm{i}}+\sum_{\mathrm{i}=1}^{4} \alpha_{\mathrm{ii}} \mathrm{X}_{\mathrm{i}}^{2}+\sum_{\mathrm{i}=1}^{3} \sum_{\mathrm{j}=\mathrm{i}+1}^{4} \alpha_{\mathrm{ij}} \mathrm{X}_{\mathrm{i}} \mathrm{X}_{\mathrm{j}}
$$

where $Y$ represents the response variables, $\alpha_{0}$ is a constant, $\alpha_{i}$ $\alpha_{\mathrm{ii}}$ and $\alpha_{\mathrm{ij}}$ are the linear, quadratic and interactive coefficients, respectively. $\mathrm{X}_{\mathrm{i}}, \mathrm{X}_{\mathrm{j}}$ are the levels of the independent variables.

Traditional hot water extraction: A water bath was used to extract polysaccharides from alpinae oxyphyllae fructus with traditional hot water extraction at the optimum extraction condition: extraction temperature of $60^{\circ} \mathrm{C}$, extraction concentration of $80 \%$ and solid/ethanol ratio of $1: 9$ based on the preliminary three-factor and three level designed orthogonal optimal experiments.

Statistical analysis: All experiments were conducted in triplicate and results are expressed as mean \pm standard deviation (SD). Analysis of variance was performed by ANOVA procedure with one factor for the determination of moisture and the diameters of inhibition zones. Statistical analysis of $t$ antibacterial activities and the content of polyphenols and flavonoids were performed by analysis of variance with two factors in the software i-Differences were considered to be significant at $\mathrm{p}<0.05$.

Extraction and determination of the total polyphenols content: Flavonoid content was determined by using a method described by Sakanaka et al. ${ }^{19}$.

The amount of total polyphenols in the extract was determined using the Folin-Ciocalteu reagent and gallic acid as standard as described by Singleton and Rossi ${ }^{20}$.

\section{RESULTS AND DISCUSSION}

The antibacterial activities influenced by different extraction concentration from 20 to $100 \%$ is shown in Fig. 1(a). The extraction was carried out under the following conditions: extraction time $1 \mathrm{~h}$, ratio of water to raw material $15 \mathrm{~mL} / \mathrm{g}$ and extract temperature $50{ }^{\circ} \mathrm{C}$. The results implied the inhibition zones of alpinae oxyphyllae fructus were enhanced to the critical value $(4.20 \pm 0.60 \mathrm{~mm})$ at extraction concentration of $80 \%$.

The inhibition zones of alpinae oxyphyllae fructus influenced by different extraction temperature from 30 to $60{ }^{\circ} \mathrm{C}$ is shown in Fig. 1(b). The extraction was carried out under the following conditions: ethanol concentration $80 \%$, ratio of water to raw material $15 \mathrm{~mL} / \mathrm{g}$ and extraction time $1 \mathrm{~h}$. The results implied the activities of alpinae oxyphyllae fructus 
enhanced to the critical value $(3.10 \pm 0.57 \mathrm{~mm})$ at extraction temperature of $50^{\circ} \mathrm{C}$ and avoiding the compounds deactivation, the temperature is less than $60{ }^{\circ} \mathrm{C}$.

The extract time is a factor that would influence the extraction efficiency. The antibacterial activities of alpinae oxyphyllae fructus affected by different ratio of water to raw material is shown in Fig. 1(c), when other parameters (extraction concentration and extraction temperature) were fixed at $80 \%$ and $50{ }^{\circ} \mathrm{C}$. The results showed that the inhibition zones began to increase to $2.80 \pm 0.32 \mathrm{~mm}$, as seen in Fig. 1(c). However, the activities of alpinae oxyphyllae fructus no longer obviously changed, when ratio of water to raw material always continued to increase. A longer extraction time also presents a positive effect on the antibacterial activities from 30 to $50 \mathrm{~min}$.
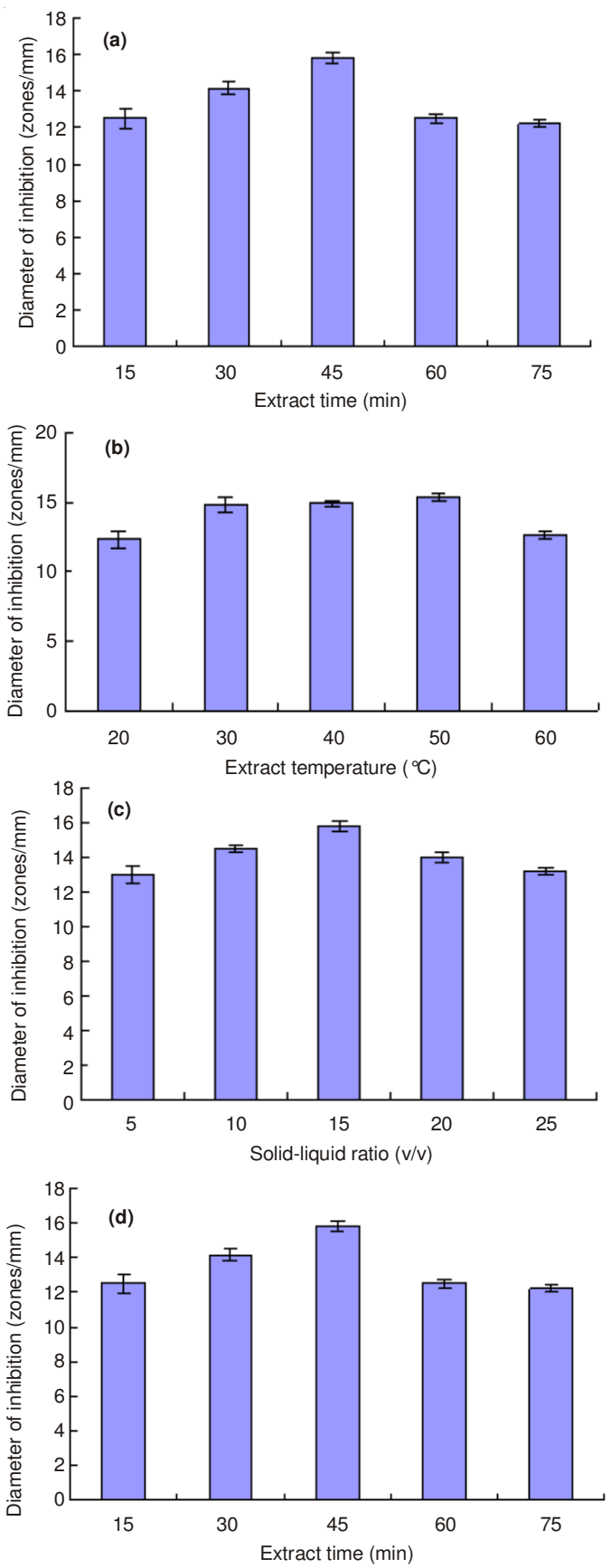

Fig. 1. Effect of ethanol concentration (a) extract temperature (b) solidliquid ratio (c) and extracting time (d) on the inhibition zones of extract
The activities of alpinae oxyphyllae fructus affected by different extraction time is seen in Fig. 1(d), when other parameters (extraction concentration, extract temperature and ratio of water to raw material) were fixed at $80 \%, 50{ }^{\circ} \mathrm{C}$ and 15 $\mathrm{mL} / \mathrm{g}$. The results indicate that there is an effect of extracting time on the activities of alpinae oxyphyllae fructus when less than $1 \mathrm{~h}$, the effect is not signifficant when extracting time is higher than $20 \mathrm{~min}$. Therefore, $45 \mathrm{~min}$ was selected as the center point of extracting time in the response surface methodology experiments as higher time will bring about the energy waste and cost increase for extraction process.

According to the single-parameter study, we adopted extraction concentration from 60 to $80 \%$, extract temperature from 35 to $55^{\circ} \mathrm{C}$, ratio of water to raw material from 10 to 20 and extraction time from 35 to 55 min for RSM experiments.

Modeling the extraction: According to the experimental design, 27 experimental results are shown in Table-1. The design matrix and the corresponding results of RSM experiments are shown in Table-1. Close agreement between experimental and predicted values was found. Result also showed that the inhibition zones ranged from 7.20 to $10.85 \mathrm{~mm}$. These conditions varied depending on the response required. Therefore, optimum process condition should be investigated in order to obtain high antibacterial activities.

\begin{tabular}{|c|c|c|c|c|c|}
\hline \multicolumn{6}{|c|}{$\begin{array}{c}\text { TABLE-1 } \\
\text { FACTORS AND LEVELS IN THE RESPONSE SURFACE DESIGN } \\
\text { ARRANGEMENT AND EXPERIMENTAL RESULTS }\end{array}$} \\
\hline No. & $\mathrm{X}_{1}$ & $X_{2}$ & $X_{3}$ & $\mathrm{X}_{4}$ & $\begin{array}{l}\text { Diameter of inhibition } \\
\text { zones }(\mathrm{mm})\end{array}$ \\
\hline 1 & 20 & 10 & 50 & 52.5 & 7.60 \\
\hline 2 & 20 & 25 & 50 & 52.5 & 7.32 \\
\hline 3 & 80 & 10 & 50 & 52.5 & 10.35 \\
\hline 4 & 80 & 25 & 50 & 52.5 & 10.39 \\
\hline 5 & 50 & 17.5 & 35 & 30 & 9.20 \\
\hline 6 & 50 & 17.5 & 35 & 75 & 8.85 \\
\hline 7 & 50 & 17.5 & 65 & 30 & 10.35 \\
\hline 8 & 50 & 17.5 & 65 & 75 & 8.70 \\
\hline 9 & 20 & 17.5 & 50 & 30 & 7.10 \\
\hline 10 & 20 & 17.5 & 50 & 75 & 7.56 \\
\hline 11 & 80 & 17.5 & 50 & 30 & 9.50 \\
\hline 12 & 80 & 17.5 & 50 & 75 & 9.50 \\
\hline 13 & 50 & 25 & 35 & 52.5 & 10.23 \\
\hline 14 & 50 & 25 & 65 & 52.5 & 9.93 \\
\hline 15 & 50 & 10 & 35 & 52.5 & 10.70 \\
\hline 16 & 50 & 10 & 65 & 52.5 & 10.51 \\
\hline 17 & 20 & 17.5 & 35 & 52.5 & 7.20 \\
\hline 18 & 20 & 17.5 & 65 & 52.5 & 7.50 \\
\hline 19 & 80 & 17.5 & 35 & 52.5 & 10.29 \\
\hline 20 & 80 & 17.5 & 65 & 52.5 & 9.50 \\
\hline 21 & 50 & 25 & 50 & 30 & 9.15 \\
\hline 22 & 50 & 25 & 50 & 75 & 8.71 \\
\hline 23 & 50 & 10 & 50 & 30 & 10.15 \\
\hline 24 & 50 & 10 & 50 & 75 & 10.78 \\
\hline 25 & 50 & 17.5 & 50 & 52.5 & 10.85 \\
\hline 26 & 50 & 17.5 & 50 & 52.5 & 10.63 \\
\hline 27 & 50 & 17.5 & 50 & 52.5 & 10.34 \\
\hline
\end{tabular}

Table-2 presents the results of fitting quadratic model to the data, the different significances of all variation sources were obtained. The effect of linear variables $\mathrm{X}_{1}$ was statistically very significant at $\mathrm{p}<0.01$; the quadratic variables $\mathrm{X}_{1} * \mathrm{X}_{1}$ and the cross variable $\mathrm{X}_{1} * \mathrm{X}_{3}$, had significant influences $(\mathrm{p}<0.05)$. 


\begin{tabular}{cccccc}
\hline \multicolumn{6}{c}{ TABLE-2 } \\
\multicolumn{5}{c}{ ANALYSIS OF VARIANCE (ANOVA) FOR THE } \\
\hline QUADRATIC POLYNOMIAL MODE \\
\hline Source & DF & SS & MS & $\mathrm{F}$ & $\mathrm{Pr}>\mathrm{F}$ \\
\hline $\mathrm{X}_{1}$ & 1 & 17.934 & 17.934 & 77.519 & 0.0001 \\
$\mathrm{X}_{2}$ & 1 & 1.9683 & 1.9683 & 8.5079 & 0.0129 \\
$\mathrm{X}_{3}$ & 1 & 0.0140 & 0.0140 & 0.0605 & 0.8097 \\
$\mathrm{tX}_{4}$ & 1 & 0.1541 & 0.1541 & 0.6662 & 0.4302 \\
$\mathrm{X}_{1} * \mathrm{X}_{1}$ & 1 & 12.093 & 12.093 & 52.274 & 0.0001 \\
$\mathrm{X}_{1} * \mathrm{X}_{2}$ & 1 & 0.0169 & 0.0169 & 0.0730 & 0.7915 \\
$\mathrm{X}_{1} * \mathrm{X}_{3}$ & 1 & 0.2970 & 0.2970 & 1.2838 & 0.2793 \\
$\mathrm{X}_{1} * \mathrm{X}_{4}$ & 1 & 0.0529 & 0.0529 & 0.2286 & 0.6411 \\
$\mathrm{X}_{2} * \mathrm{X}_{2}$ & 1 & 0.0098 & 0.0098 & 0.0424 & 0.8401 \\
$\mathrm{X}_{2} * \mathrm{X}_{3}$ & 1 & 0.0625 & 0.0625 & 0.2701 & 0.6126 \\
$\mathrm{X}_{2} * \mathrm{X}_{4}$ & 1 & 0.2916 & 0.2916 & 1.2604 & 0.2835 \\
$\mathrm{X}_{3} * \mathrm{X}_{3}$ & 1 & 0.7939 & 0.7939 & 3.4318 & 0.0886 \\
$\mathrm{X}_{3} * \mathrm{X}_{4}$ & 1 & 0.4225 & 0.4225 & 1.8262 & 0.2014 \\
$\mathrm{X}_{4} * \mathrm{X}_{4}$ & 1 & 3.9636 & 3.9636 & 17.132 & 0.0013 \\
Model & 14 & 36.707 & 2.6219 & 11.333 & 0.0001 \\
(Linear) & 4 & 20.070 & 5.0176 & 21.688 & 0.0001 \\
$($ Quadratic) & 4 & 15.493 & 3.8733 & 16.742 & 0.0001 \\
$($ Cross Product) & 6 & 1.1434 & 0.1905 & 0.8237 & 0.5728 \\
Error & 12 & 2.7761 & 0.2313 & & \\
(Lack of fit) & 10 & 2.6453 & 0.2645 & 4.0427 & 0.2144 \\
(Pure Error) & 2 & 0.1308 & 0.0654 & & \\
Total & 26 & 39.483 & & & \\
\hline & & & & & \\
\hline
\end{tabular}

And as the model value was at $\mathrm{p}<0.05$ and lack of fit value was at $\mathrm{p}>0.1$, it means that this model can predict experiment results exactly. And the final predictive equation obtained was as follows:

$$
\begin{gathered}
Y_{1}=16.60667+1.2225 * X_{1}+0.405 * X_{2}+0.034167 * X_{3} \\
-0.113333 * X_{4}-1.505833 * X_{1} * X_{1}-0.065 * X_{1} * X_{2} \\
-0.2725 * X_{1} * X_{3}-0.115 * X_{1} * X_{4}+0.042917 * X_{2} * X_{2} \\
+0.125 * X_{2} * X_{3}+0.27 * X_{2} * X_{4}-0.385833 * X_{3} * X_{3} \\
-0.325 * X_{3} * X_{4}-0.862083 * X_{4} * X_{4}
\end{gathered}
$$

and in conclusion, by observing linear and quadratic coefficients, we concluded that the order of factors influencing the response value of the extraction yield of flavonoids was as follows: ethanol concentration $>$ extract temperature $>$ extract time $>$ the solid-liquid ratio.

Validation of the models: Based on the experimental data, the maximum predict for the extraction of alpinae oxyphyllae fructus was obtained under the following conditions: ethanol concentrations $73 \%$, extract temperature $54{ }^{\circ} \mathrm{C}$, liquid-material ratio 15 and extract time $46 \mathrm{~min}$. The predicted diameter of inhibition zones was $10.43 \mathrm{~mm}$, which was consistent with the practical of $10.57 \mathrm{~mm}$. The strong correlation between the real and predicted results confirm that the response model was adequate to reflect the expected optimization.

Comparison of traditional hot water extraction and ultrasonic/microwave assisted extraction: This higher efficiency, $10.43 \mathrm{~mm}$ of the diameter, comparing with $8.83 \mathrm{~mm}$ of traditional hot water extraction, lead to application of ultrasonic/microwave assisted extraction for alpinae oxyphyllae fructus. This is because ultrasound and microwave radiation could accelerate the extracting process and may improve extraction of bioactive compounds ${ }^{21,22}$. Simultaneously, the possible benefits of ultrasound in extraction are mass transfer intensification, cell disruption, improved penetration and capillary effects $^{12}$. It was confirmed that UMAE should be an appropriate and effective extraction technique for extract from alpinae oxyphyllae fructus because of the maximum extraction values.

Antibacterial activities correlation with polyphenols and flavonoid content: In addition extracts on the basis of total polyphenols extraction, on average, the content of total polyphenols and flavonoids was $7.34 \pm 0.19 \%$ and $5.95 \pm$ $0.32 \%$.

Fig. 2 presents diameters of inhibition zones exerted by the total polyphenols and flavonoids extract and the two standards towards tested microorganisms. The extract was effective against the Gram-negative strain (E. coli). The diameters of inhibition zones was higher with higher total polyphenols and flavonoids content. The activity of total polyphenols was lower than that of total flavonoids.
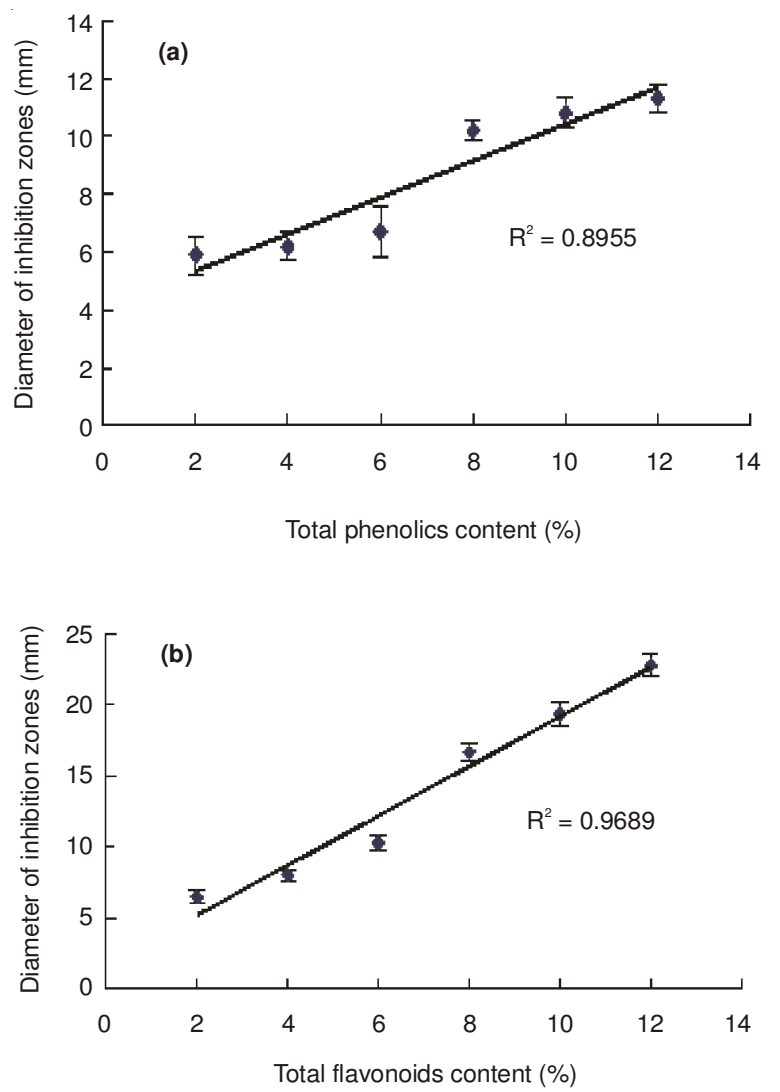

Fig. 2. Total polyphenol (a) and flavonoids content (b) against E. coli

There was strong correlation between total polyphenols content and inhibition of bacteria when each concentration tested polyphenols $(\mathrm{r}=0.84, p=0.007)$ while the total flavonoid with more significant strong correlation $(\mathrm{r}=0.93, p=$ 0.006). Results from this study suggest that polyphenol compounds are responsible of the antibacterial activity of extract of alpinae oxyphyllae fructus.

One of the largest classes of naturally-occurring polyphenol compounds are the flavonoids ${ }^{23}$. A number of flavones, flavonols, flavanones and isoflavones, as well as some of their methoxy, isoprenyl and acylated derivatives, show antibacterial activity $^{24}$. It is evident that a structure-activity relationship exists between the various flavonoids and their antimicrobial activity. The advantage of such a synergistic effect is not stronger 
activity, but also a reduction in the quality of the agent and fewer consequent side effects $2^{5}$.

Numerous works have reported the antibacterial effects of these metabolites against a wide range of bacteria. Polyphenol compounds are known to be synthesized by plants in response to microbial infection ${ }^{26,27}$; it is therefore logical that they have been found in vitro to be effective antimicrobial substances against a wide array of micro-organisms ${ }^{28}$.

MIC of alpinae oxyphyllae fructus extract: Quantitative evaluation of the antibacterial activity of the extract of alpinae oxyphyllae fructus fruit and of the standards was carried out against selected microorganisms; the MICs of the tested samples are presented in Table-3. MIC values of the alpinae oxyphyllae fructus was lower for $S$. aureus while it was a more potent inhibitor of $S$. aureus and much less efficient against $E$. coli. In the case, alpinae oxyphyllae fructus gave comparable MIC of $E$. coli $(3.00 \mathrm{mg} / \mathrm{mL})$ compared to that of $S$. aureus $(1.50$ $\mathrm{mg} / \mathrm{mL})$. This is consistent with previous studies reporting that Gram-negative bacteria are more resistant to antimicrobials than Gram-positive microorganisms due to their outer lipopolysaccharide membranes ${ }^{29,30}$.

\begin{tabular}{lccccccc}
\multicolumn{8}{c}{ TABLE-3 } \\
MINIMUM INHIBITORY CONCENTRATION (MIC) OF \\
ALPINAE OXYPHYLLAE FRUCTUS EXTRACT \\
\hline \multirow{2}{*}{ Strain } & \multicolumn{7}{c}{ MIC of alpinae oxyphyllae fructus $(\mu \mathrm{g} / \mathrm{mL})$} \\
\cline { 2 - 8 } & 48.00 & 24.00 & 12.00 & 6.00 & 3.00 & 1.50 & 0.75 \\
\hline E. coli & - & - & - & - & - & + & + \\
S. aureus & - & - & - & - & - & - & + \\
\hline + growth of microbe; - outgrowth of microbe. &
\end{tabular}

\section{Conclusion}

The results of this study confirmed the optimum conditions, of which results showed high antibacterial activities comparing with traditional hot water extraction. The MIC of alpinae oxyphyllae fructus extracts, demonstrated significant antibacterial activities against $E$ coli. and $S$. aureus. Further, the results exhibited the content of total polyphenols and flavonoids correlation with the antibacterial activities was significant. Thus, there may be caution with the use of these extracts as food additives and more studies should be performed concerning their safety and toxicity.

\section{ACKNOWLEDGEMENTS}

This work was supported by the Natural Science Foundation of Hainan Province of China (312073, 211008).

\section{REFERENCES}

1. X. Yu, L. An, Y. Wang, H. Zhao and C. Gao, Toxicol. Lett., 144, 205 (2003).

2. G.F. Shi, L.J. An, B. Jiang, S. Guan and Y.M. Bao, Neurosci. Lett., 403, 206 (2006).

3. G. Shui, Y.M. Bao, J. Bo and L.J. An, Eur. J. Pharmacol., 538, 73 (2006).

4. X. Zhang, G.F. Shi, X.Z. Liu, L.J. An and S. Guan, Cell Biochem. Funct., 29, 342 (2011).

5. X. Chen, Y. Jia and B. Wang, Chung Kuo Chung Yao Tsa Chih, 17, 107 (1992).

6. W.H. Lee and J.C. Chung, J. Kor. Oriental Intern. Med., 19, 381 (1998).

7. B.S. Koo, W.C. Lee, Y.-C. Chang and C.-H. Kim, Phytother. Res., 18, 142 (2004).

8. K. Lau, W.G. McLean, D.P. Williams and C.V. Howard, Toxicol. Sci., 90, 178 (2006)

9. V.K. Bajpai and S.C. Kang, J. Biosci., 35, 533 (2010).

10. B. Yang, F. Chen, Y.L. Hua, S.S. Huang, S. Lin, L.R. Wen and Y. Jiang, Food Chem., 131, 508 (2012).

11. S. Hemwimon, P. Pavasant and A. Shotipruk, Sep. Purif. Technol., 54, 44 (2007).

12. Y. Iida, T. Tuziuti, K. Yasui, A. Towata and T. Kozuka, Innov. Food Sci. Emerg. Technol., 9, 140 (2008).

13. C. Tringali, Taylor \& Francis group, London (2001).

14. Y. Chen, X. Gu, S. Huang, J. Li, X. Wang and J. Tang, Int. J. Biol. Macromol., 46, 429 (2010).

15. C. Ao, A. Li, A.A. Elzaawely, T.D. Xuan and S. Tawata, Food Contr., 19, 940 (2008).

16. I.C. Zampini, M.A. Vattuone and M.I. Isla, J. Ethnopharmacol., 102, 450 (2005).

17. X.P. Chen, W.X. Wang, S.B. Li, J.L. Xue, L.J. Fan, Z.J. Sheng and Y.G. Chen, Carbohydr. Polym., 80, 944 (2010).

18. Y. Gong, Z.Q. Hou, Y.X. Gao, Y.S. Xue, X. Liu and G.M. Liu, Food Bioprod. Process., 90, 9 (2012).

19. S. Sakanaka, Y. Tachibana and Y. Okada, Food Chem., 89, 569 (2005).

20. V. Singleton and J.A. Rossi, Am. J. Enol. Vitic., 16, 144 (1965).

21. B. Yang, M. Zhao, J. Shi, N. Yang and Y. Jiang, Food Chem., 106, 685 (2008).

22. M. Sališová, Š. Toma and T.J. Mason, Ultrason. Sonochem., 4, 131 (1997).

23. T.A. Geissman, D.H.G. Crout, Organic Chemistry of Secondary Plant Metabolism, Freeman, Cooper \& Company, p. 183 (1969).

24. J.B. Harborne and C.A. Williams, Phytochemistry, 55, 481 (2000).

25. W. Bylka, I. Matlawska and N.A. Pilewski, J Am. Nutraceutical Assoc., 7, 24 (2004).

26. J.H. Doughari and S. Manzara, Afr. J. Pharm. Pharmacol., 2, 67 (2008).

27. M. Sengul, H. Yildiz, N. Gungor, B. Cetin, Z. Eser and S. Ercili, Pak. J. Pharm. Sci., 22, 102 (2009).

28. M.M. Cowan, Clin. Microbiol. Rev., 12, 564 (1999).

29. R. Khan, B. Islam, M. Akram, S. Shakil, A.A. Ahmad, S.M. Ali, M. Siddiqui and A.U. Khan, Molecules, 14, 586 (2009).

30. N.S. Al-Zoreky, Int. J. Food Microbiol., 134, 244 (2009). 